\title{
Da emissão à recepção: a construção do endereçamento em vídeos, produzidos por graduandos em Ciências Biológicas, destinados à estudantes do ensino básico
}

\author{
From broadcasting to reception: the construction of addressing in vídeos, produced by \\ undergraduate students in Biological Sciences, aimed at primary school students \\ De la radiodifusión a la recepción: la construcción del direccionamiento en vídeos, producidos por \\ estudiantes de grado en Ciencias Biológicas, dirigidos a estudiantes de educación primaria
}

Recebido: 09/12/2021 | Revisado: 17/12/2021 | Aceito: 22/12/2021 | Publicado: 04/01/2022

\author{
Renato Campos Vieira \\ ORCID: https://orcid.org/0000-0001-6763-7733 \\ Universidade Federal do Rio de Janeiro, Brasil \\ E-mail: renatovieirabio@gmail.com \\ Luiz Augusto Coimbra de Rezende Filho \\ ORCID: https://orcid.org/0000-0002-8845-3025 \\ Universidade Federal do Rio de Janeiro, Brasil \\ E-mail: luizrezende.ufrj@gmail.com
}

\begin{abstract}
Resumo
Atualmente o uso de vídeos em aulas de ciências é cada vez mais comum. Segundo pesquisas anteriores, o gênero documentário geralmente é o mais utilizado, pois apresenta o conteúdo de forma mais clara e de acordo com a realidade. Porém, muitas vezes os estudantes costumam achar este tipo de gênero entediante. Desta maneira, o que é necessário para que um filme funcione para um determinado público? O objetivo deste trabalho foi o de compreender a relação dos conhecimentos mobilizados durante a produção de dois vídeos, realizados por graduandos em Ciências Biológicas, destinados à estudantes do ensino básico, e elucidar se o público pretendido se colocou, de fato, na posição idealizada pelos produtores. Para o estudo da produção, foram analisados os vídeos gerados, bem como a entrevista realizada com os graduandos. Já para a etapa de recepção, foram analisados os questionários respondidos pelos espectadores, após a exibição dos vídeos. O conceito de circularidade da mensagem no processo de comunicação e o endereçamento audiovisual, propostos por Stuart Hall e Elizabeth Ellsworth, respectivamente, servem de base para entender o processo comunicativo em sala de aula. Como conclusão, os graduandos fizeram escolhas conscientes, tendo em mente o público desejado e, apesar dos espectadores, em sua maioria, terem feito uma leitura de concordância das obras exibidas, ainda assim houve pontos de resistência. Estes resultados indicam que houve uma negociação de sentidos pelos espectadores, sendo que estes, por sua vez, participaram ativamente na construção de significado dentro do processo comunicativo.
\end{abstract}

Palavras-chave: Produção e recepção de vídeos; Endereçamento; Ensino de ciências.

\begin{abstract}
Currently, the use of videos in science classes is increasingly common. According to previous investigations, the documental genre is generally the most used because it presents the content in a clearer way and accords with reality. However, students often find this type of genre boring. So, what does it take for a film to work for a specific audience? The objective of this work was to understand the relation of knowledge mobilized during the production of videos, carried out by undergraduate students in Biological Sciences, aimed at primary students, and to clarify if the intended audience has placed itself, in fact, in the idealized place by video producers. For the production study, the generated videos were analyzed, as well as the interview carried out with the producers. During the reception stage, after the vídeos were shown, the questionnaires answered by the spectators were analyzed. The concept of message circularity in the communicative process and the audiovisual adressing, proposed by Stuart Hall and Elizabeth Ellsworth, respectively, serve as a basis for understanding the communicative process in the classroom. As a conclusion, the undergraduate students made conscious decisions, having in mind the target audience, and, despite the fact that the majority of the spectators had read the videos shown according to the ideas of the producers, there were some resistance points. These results indicate that there was a negotiation of meanings by the spectator, and these, in turn, actively participated in the construction of meaning within the communicative process.
\end{abstract}

Keywords: Video production and reception; Addressing; Science teaching. 


\begin{abstract}
Resumen
Actualmente, el uso de videos en las clases de ciencias es cada vez más común. Según investigaciones previas, el género documental es generalmente el más utilizado porque presenta el contenido de forma más clara y acorde con la realidad. Sin embargo, los estudiantes a menudo encuentran aburrido este tipo de género. Entonces, ¿qué se necesita para que una película funcione para un público determinado? El objetivo de este trabajo fue comprender la relación de los conocimientos movilizados durante la producción de dos videos, realizados por estudiantes de pregrado en Ciencias Biológicas, dirigidos a estudiantes de primaria, y dilucidar si el público objetivo estaba, de hecho, en el puesto idealizado por los productores de video. Para el estudio de la producción se analizaron los videos generados, así como la entrevista realizada a los productores. En cuanto a la etapa de recepción, los cuestionarios respondidos por los espectadores fueron analizados luego de mostrados los videos. El concepto de circularidad del mensaje en el proceso comunicativo y el direccionamiento audiovisual, propuesto por Stuart Hall y Elizabeth Ellsworth, respectivamente, sirven de base para comprender el proceso comunicativo en el aula. Como conclusióno, los estudiantes de pregrado tomaron decisiones conscientes, teniendo en cuenta la audiencia deseada y, apesar de que la mayoría de los espectadores habían leído las obras mostradas según las ideas de los productores, aún existían puntos de resistência. Estos resultados indican que hubo una negociación de significados por parte de los espectadores, quienes, a su vez, participaron activamente en la construcción de significados dentro del proceso comunicativo.
\end{abstract}

Palabras clave: Producción y recepción de videos; Direccionamiento; Enseñanza de las ciencias.

\title{
1. Introdução
}

É cada vez mais comum, nas últimas décadas, o uso de vídeos para o ensino de ciências (Duarte, 2005; Santos \& Arroio, 2009, Pretto, 2013). Sua inserção crescente no ensino se dá principalmente pelo fato de tornar visível o invisível, ao mostrar diversos tipos de fenômenos (Hegarty, 2004), assim como permite maior compreensão das subjetividades e cultura do outro (Ferreira \& Rezende filho, 2021), e dessa maneira, abre-se um caminho para o encontro com a alteridade (Fresquet, 2013). Porém, na maioria das vezes, o gênero preferido pelos professores é o documentário (Bruzzo, 1998; Vidal \& Rezende filho, 2010), por trazer o conteúdo de forma mais objetiva para a atingir a finalidade de certas disciplinas. Dessa forma, há o risco de tornar a atividade com o vídeo não muito diferente de uma aula tradicional, no estilo emissor-receptor (Rezende filho \& Struchiner, 2009). Este tipo de ensino e aprendizagem segue o estilo de educação bancária (Freire, 1996), sendo este aquele em que a participação dos alunos nos processos de construção de sentido é ignorada. Neste caso, o receptor do conhecimento é considerado apenas como sujeito receptáculo de conhecimento já acabado. Sendo assim, ao tratar o vídeo como possuidor de um conhecimento pronto, e que ao chegar em sala de aula irá solucionar os objetivos da aula, de forma igual e transparente para todos, é também ignorar a participação ativa dos espectadores nos processos de construção de sentido. A linguagem audiovisual possui suas especificidades e mecanismos próprios, e é composta por elementos que são codificados e em conjunto, transmitem significados desejados por quem o produziu. O espectador, por sua vez, ao contrário da passividade, também constrói sua visão de mundo a partir do que está assistindo, ao decodificar a mensagem a partir de suas próprias experiências e vivências.

Hall (2003) esboça um modelo teórico que tem como objetivo os processos de comunicação em seu caráter compartilhado entre emissor e receptor, no sentido em que os dois lados participam do processo e tem igual relevância, e assim, contribuem de maneira circular. A partir do entendimento de que uma mensagem audiovisual é codificada e como consequência, será decodificada, e que neste processo estão envolvidas questões cultuais, sociais e identitárias, a importância da inserção do conceito de endereçamento na construção de um audiovisual se torna uma questão emergente a se levar em consideração. Segundo Elizabeth Ellsworth (2001), toda produção audiovisual almeja um determinado público e, para isso, é constituída por mecanismos que visam convocar o espectador a ver e entender a obra a partir de um ponto de vista. Sendo assim, para que um filme "funcione", ele precisa entrar em um diálogo com seu espectador, e para isso, se torna necessário conhecer o contexto, gosto e preferências do público-alvo, e assim, tecer estratégias para que a mensagem faça sentido para quem está assistindo.

Então, para elucidar os processos de codificação e decodificação de uma produção audiovisual, o objetivo desta 
pesquisa foi o de compreender como se dá o processo de circularidade do processo comunicativo através da exibição de dois audiovisuais produzidor por graduandos do curso de Biologia, destinados à alunos do ensino básico. Este estudo tem como potencial contribuir para o entendimento em relação às dinâmicas comunicativas que envolvem os audiovisuais em sala de aula, e assim, promover maior autonomia dos professores, quando estes forem desenvolver novas práticas com tal tecnologia.

\section{Metodologia}

Trata-se de uma pesquisa qualitativa (Lüdke \& André, 2014), sendo esta uma característica de investigações que procuram entender os aspectos subjetivos de fenômenos sociais e humano. Neste caso, foi feito um estudo de caso, em que houve participação direta do pesquisador com os sujeitos participante, e que, segundo Yin (2001), trata-se de "uma investigação empírica de um fenômeno contemporâneo dentro de seu contexto da vida real, especialmente quando os limites entre o fenômeno e o contexto não estão claramente definidos" (p. 32).

Os dois vídeos selecionados para esta análise foram produzidos por duas equipes, compostas por três graduandos cada, durante o semestre de 2018.1 e 2019.1, a partir de uma atividade de formação para estudantes de graduação do curso de Ciências Biológicas da Universidade Federal do Rio de Janeiro. Esta intervenção aconteceu no contexto de uma disciplina de Ecologia, relacionada à prática como conteúdo pedagógico. Segundo Cabral \& Pereira (2019), "a incorporação de estratégias de letramento audiovisual por meio da realização de oficinas de produção de vídeos é capaz de favorecer a prática pedagógica, podendo contribuir para o aprendizado, integração dos alunos e, sobretudo, fomentando o exercício da prática de comunicação em ciências" (p. 1226).

A proposta de formação teve como objetivo incluir não só um conhecimento sobre a linguagem e a história do cinema, mas também sobre as teorias do espectador, o que emerge não só da vivência do professor com seus alunos, mas do mundo que os cerca e que thes fornece referências e informação, que orienta seus gostos, preferências e saberes. Assim, não só seria necessário "formar" o professor conceitualmente para perceber o que são e como atuam os modos de endereçamento, mas também como construí-los, a partir de que bases e de que conhecimentos sobre seus espectadores, sugerindo-lhes um método para essa construção.

A atividade de produção teve início em sala de aula, e se desenvolveu a partir de alguns pontos a serem considerados a seguir: Primeiramente, a partir dos resultados de pesquisas de um artigo (Rezende filho \& Struchiner, 2009) e da exposição de um panorama histórico, foi feita a reflexão sobre o cenário atual e identificados possíveis meios de se produzir novas práticas pedagógicas com o audiovisual. Em seguida, houve explanação sobre a circularidade do processo comunicativo (Hall, 2003) e do conceito de endereçamento (Ellsworth, 2001) e, logo depois, foi feita a reflexão sobre os elementos constituintes de um vídeo. Alguns vídeos produzidos por estudantes da mesma disciplina, em semestres anteriores, foram selecionados com o objetivo de identificar e analisar os elementos de endereçamento presentes e tentar compreender a importância de se ter conhecimento sobre este conceito.

Já em um segundo momento, agora em campo, as atividades foram divididas em quatro práticas, três de conteúdo ecológicos e uma de elaboração do vídeo sobre uma das práticas anteriores. Para o desenvolvimento do processo criativo e de construção do vídeo, três temas foram selecionados a partir do currículo da disciplina relacionados a: interações ecológicas, quantidade de espécie dentro de uma determinada área ou ecossistema de riacho. A atividade consistia em transpor o que foi visto em campo para um vídeo, de forma com que estes fossem elaborados para que se criasse um diálogo com o estudante do ensino básico. A professora da disciplina dividiu as equipes, sendo que os dois grupos selecionados para esta pesquisa produziram vídeos em que o conteúdo "interações ecológicas" foi abordado. Dentre as possibilidades de tema que poderiam ser explorados no vídeo, a partir da prática em campo, estavam as interações do tipo parasitismo, predadorismo, inquilinismo, 
herbivorismo, entre outros tipos encontradas na natureza e que foram exploradas pelos monitores da disciplina ao longo da trilha. Foi explanado que o vídeo poderia abordar de forma ampla e diversa o que foi visto durante a atividade, e que o importante era se ter em mente o público escolhido e a partir daí tecer estratégias para transpor o que foi aprendido em campo para um vídeo. Os graduandos utilizaram seus celulares para as gravações e foram orientados a encontrar a melhor forma de expressão narrativa, técnica e dramatúrgica para aquelas ideias, ou seja, quais seriam as melhores estratégias para que suas produções pudessem chegar ao público-alvo e que estes se colocassem no lugar determinado pelos produtores: aprender ciências.

Esta primeira etapa do processo formativo teve como objetivo compreender como se deu o processo de aprendizagem em relação à produção de vídeos a partir do conceito de endereçamento e circularidade da mensagem. Para a coleta de dados, todos os seis produtores foram entrevistados remotamente. As análises da identificação do endereçamento dos vídeos, bem como as estratégias utilizadas, foram feitas a partir da descrição do vídeo e seguiu as orientações gerais da Análise Fílmica Francesa (Vanoye \& Goliot-lété, 2008). Esta descrição dos elementos de endereçamento se torna importante pois permite identificar as intenções dos produtores, ou seja, elucidar qual seria o seu significado preferencial, sendo este o sentido pretendido e desejado pelos produtores (Hall, 2003). Já as análises em relação a construção do endereçamento foram realizadas durante a produção, a partir da observação e anotações do pesquisador em campo e, posteriormente, pelas entrevistas com os produtores.

Já para a etapa do estudo de recepção das duas obras selecionadas, foi realizada, em outubro de 2019, uma exibição dos vídeos em uma escola municipal situada na cidade do Rio de Janeiro. Esta atividade aconteceu em uma feira de ciências em que os alunos expunham seus trabalhos, bem como participavam de atividades desenvolvidas por estudantes da UFRJ. Uma das salas continha uma atividade intitulada "Atividades em campo: aventuras de estudantes de Biologia". Nesta atividade, os alunos do ensino básico, separados em cinco grupos, entravam em uma sala equipada com projetor e caixa de som para assistirem aos vídeos. Neste estudo de recepção, o objetivo foi identificar a posição adotada pelos estudantes, estes sendo os espectadores imaginados pelos produtores, no sentido de entender se houve aceitação, negociação ou oposição ao significado preferencial proposto em cada produção (Rezende Filho, et al., 2015).

De acordo com Hall (2003), no processo de comunicação, o espectador pode ler e interpretar, ou decodificar a mensagem partir de três atitudes: (1) a mensagem transmitida é decodificada segundo referencias da sua construção, ou seja, do mesmo modo como os produtores idealizaram (posição preferencial ou dominante); (2) o sentido da mensagem pode ser negociado de acordo com as condições particulares do espectador (posição negociada), (3) ou simplesmente quando o espectador interpreta a mensagem a partir de uma concepção alternativa ou de oposição (posição de oposição) em relação àquelas que está sendo transmitida. Entretanto, os espectadores movimentam-se entre essas posições, cabendo "ao trabalho empírico dizer, em relação a um texto particular e a uma parcela específica da audiência, quais as leituras que estão operando" (Hall, 2003, p. 113).

Para a análise do processo de recepção dos vídeos, após a exibição, os espectadores de cada seção foram convidados a responder um questionário composto por quatro perguntas discursivas, sendo elas: (1) Destaque pontos positivos e pontos negativos do vídeo que chamaram a sua atenção; (2) Se você fosse produzir esse vídeo você faria algo diferente? O quê/como? (3) Ao assistir esse vídeo, você se identificou com algum personagem, alguma música ou com alguma situação exibida? Caso você tenha se identificado, explique o motivo; (4) O que você pode dizer que você entendeu nesse vídeo? 


\section{Resultados e Discussão}

\subsection{O estudo da produção audiovisual: a análise da construção do endereçamento audiovisual por graduandos em}

\section{Ciências Biológicas}

O estudo da produção audiovisual procurou elucidar, primeiramente, através da análise dos vídeos escolhidos, quais características estéticas, narrativas e técnicas foram utilizadas pelos produtores, para que, a partir disto, fosse possível interpretar como imaginaram o público pretendido. Já a entrevista, a qual foi transcrita e analisada a partir do método de análise de conteúdo, proposto por Bardin (2016), procurou compreender quais foram as reais intenções dos produtores e como se deu o processo de construção da obra.

\subsubsection{Vídeo 1: Flora: a aventureira ${ }^{1}$}

O vídeo é uma paródia da animação infantil "Dora a aventureira" e mostra a personagem principal, tendo seu nome alterado para "Flora", em uma aventura no meio da floresta. Os vídeos destinados ao público infantil, por sua vez, possuem características de endereçamento muito marcantes, como estruturas narrativas padronizadas, personagens carismáticos, humanização de animais, cores vivas, trilhas sonoras lúdicas, entre outros elementos estéticos que cumprem o papel de encantar a criança e a de deixar interessadas por aquilo que estão assistindo.

$\mathrm{Na}$ jornada, a protagonista Flora aparece de forma caracterizada, como no desenho em que aparece sempre carregando sua mochila nas costas, e convida o público a se aventurar, em sua companhia, no meio da floresta. Ao longo da caminhada, encontra alguns personagens coadjuvantes, também caracterizados que, por vezes ajudam a protagonista a tirar suas dúvidas em relação aos conhecimentos científicos com que se depara em campo e, em outros momentos, apenas atrapalham sua jornada. Durante todo o vídeo, Flora conversa com seus espectadores sempre que surge uma situação que gera incerteza. Estas dúvidas são respondidas pela voz narradora ou pelos personagens ajudantes que acompanham a protagonista. Porém, em todos os momentos há uma conversa direta com o público, tal como na animação que serve de referência ao vídeo.

Toda a aventura serve de apoio para a explicação de algumas situações em que as interações ecológicas aparecem durante a jornada da dupla, como o mutualismo, quando as personagens mostram líquens em uma árvore e explicam o que está acontecendo, o herbivorismo, no exemplo onde mostram folhas com marcas de mastigação de predadores, além de exemplo de parasitismo e o comensalismo. Durante toda a aventura são utilizadas figuras na tela para exemplificar o que estão falando, legendas explicativas e trilha sonoras, como a música "hakuna matata" da animação dos estúdios Disney "O Rei Leão3 .

O endereçamento para o público infantil pôde ser identificado na personagem de Flora que é interpretada de forma infantilizada, bem como na utilização de músicas infantis. Além disso, ao longo da produção, são perceptíveis os traços da estrutura de narrativa de acordo com a jornada do herói (Gancho, 2006). Esse tipo de narrativa é muito utilizado em filmes e animações infantis de grandes produções, como as de Hollywood, por exemplo. Esta fórmula se ancora em elementos que prendem a atenção dos espectadores, que os fazem torcerem, ter raiva, ou seja, que tentam causar uma aproximação do público com aquilo que estão assistindo. O estilo narrativo da jornada do herói é bastante marcado por momentos que servem para conduzir uma história e ao mesmo tempo cativar o grande público.

Após a decupagem e a análise das partes do vídeo, sendo conferidas com detalhes as estruturas, trilha sonora, linguagem utilizada, a estética etc., ainda que tenha havido preocupação em relação aos elementos de endereçamento para o público infantil, se pode perceber os conteúdos científicos bastante enfatizados e em primeiro plano, sendo este o objetivo

\footnotetext{
${ }^{1} \mathrm{O}$ vídeo encontra-se disponível no canal "ambientalizando UFRJ”. A postagem da obra foi autorizada por seus realizadores através da assinatura do termo de autorização de imagem e som. Segue o link: 〈https://youtu.be/sfdhx5qO63o>

${ }^{2}$ Dora a aventureira - Criadores: Chris Gifford, Valerie Walsh, Eric Weiner; Emissora original: Nickelodeon; Ano: 1999; País: EUA; Título original: Dora the Explorer

${ }^{3}$ O Rei Leão - Direção: Rob Minkff, Rogers Allers; Ano: 1994; País: EUA; Título original: The Lion King; Distribuidora: Walt Disney
} 
principal do vídeo: transmitir o conteúdo curricular aprendido em campo para as crianças. Esta alegação foi confirmada pelos produtores, quando foram indagados a respeito de qual teria sido o significado preferencial do vídeo: "no final a gente queria que a criança aprendesse aquele conteúdo, então, passar essa informação era o principal, só estávamos buscando rotas pra buscar essas informações menos quadradinhas, de sala aula".

Segundo os próprios produtores, a intenção foi mostrar as interações da natureza, abrangendo todas elas de um jeito simples. Para isso, pensaram de forma consciente em trazer uma personagem conhecida do público do sexto ano, este constituído por crianças entre 11 e 13 anos, juntamente com a caracterização de cada integrante, além da voz de um narrador durante a aventura, as falas mais infantilizadas, a trilha sonora, adição de imagens e textos extras para a explicação de conceitos científicos. Assim, em um vídeo com objetivos de ensinar, por exemplo, o conteúdo se insere no meio de encenações e, dessa forma, pode se tornar mais atrativo e prazeroso, assim como as explicações na maioria das vezes é feita em uma linguagem que faz com que o público infantil compreenda mais facilmente o que está assistindo.

Os produtores relataram acreditar que se tivessem adicionado outros elementos de endereçamento com o objetivo de atingir outros públicos, como os alunos de ensino médio, por exemplo, teriam trabalhado a personalidade da personagem Flora como um tom mais irônico, engraçada e piadista. Nos relatos dizem que, pelo fato de a personagem original "Dora" ter se tornado um meme entre os adolescentes, isto poderia ter sido trabalhado de forma a trazer o interesse dos mais adolescentes também. Mesmo assim, acreditam que o vídeo é adequado para se obter conhecimentos básicos para um público infantil, no sentido de estimular um olhar biológico ao observar as interações ao seu redor, bem como para recapitular tópicos para um público mais adolescente.

Um fato interessante em relação à escolha do endereçamento, relatado na entrevista, é que se tivessem escolhido o público de ensino superior, por exemplo, teriam colocado o máximo de conteúdos possíveis, com mais detalhes, "uma coisa mais chata", de acordo com um dos integrantes do grupo. Contudo, como o objetivo era o endereçamento para o público do ensino fundamental, se sentiram mais à vontade de abordar o conteúdo de forma mais lúdica.

Ao final, os produtores afirmam que o conhecimento do conceito de endereçamento, visto no momento de formação, foi essencial para a realização da atividade, pois tiveram uma noção maior na forma de enxergar o público-alvo e em como produzir um audiovisual educativo mais direcionado.

\subsubsection{Vídeo 2 - Caexplora \& Curupira ${ }^{4}$}

Os produtores integrantes deste grupo optaram por contar uma história baseada em uma figura do folclore, que é o Curupira, e adicionaram uma segunda personagem para cumprir o papel de exploradora ao lado da figura mitológica. $\mathrm{Na}$ aventura, duas integrantes do grupo interpretam as personagens Curupira e Caexplora, e juntas desbravam a floresta. No caminho encontram um desmatador, interpretado por outro integrante, e o convidam a adentrar a mata. Ao longo da jornada, ensinam ao desmatador e ao público sobre a importância da preservação das florestas, bem como as interações ecológicas que ocorrem em seu interior. Ao final da história o desmatador se torna consciente de seu erro e o trabalho das duas personagens se completa.

Mais uma vez a história se desenvolve conforme a estrutura de narrativa no estilo da jornada do herói (Gancho, 2006) e serve para apresentar alguns conteúdos da disciplina de ciências e ao mesmo tempo entreter o público envolvido, que neste caso, também é destinado ao público do ensino fundamental II. As heroínas agora são duas, e o papel do antagonista, por sua vez, fica com o desmatador. Existe ainda a personagem aliada às protagonistas, que fica por conta da pesquisadora,

\footnotetext{
${ }^{4}$ O vídeo encontra-se disponível no canal "ambientalizando UFRJ". A postagem da obra foi autorizada por seus realizadores através da assinatura do termo de autorização de imagem e som. Segue o link: < https://youtu.be/yPD13u9hDO8>.
} 
interpretada por uma quarta integrante do grupo. Pontos importantes a serem destacados são as caracterizações dos personagens, a trilha sonora, bem como a linguagem mais simples utilizadas pelos atores e atrizes, que, apesar de serem endereçadas ao público infantil, não são infantilizadas. Ao final da aventura, os produtores optaram por exibir um compilado de erros de gravação, prática comum em filmes de comédia, por exemplo.

Assim como no vídeo anterior, trabalharam os principais tipos de interações vivenciadas em campo, como o mutualismo na interação entre algas e fungos, e entre a vegetação e as formigas, como também trouxeram exemplos de inquilinismo e competição. Porém, aproveitaram a narrativa criada, com a adição do personagem do desmatador, para trabalharem a importância da preservação das florestas. No início da aventura, as protagonistas avistam o desmatador tentando cortar árvores ao seu redor e a partir deste acontecimento começam um processo de conscientização, tanto do desmatador, quanto do público.

Segundo os produtores do vídeo, preferiram um olhar mais voltado para a conscientização e preservação da natureza, associando o tema com o folclore brasileiro de forma lúdica. $\mathrm{Na}$ entrevista, relataram que quiseram produzir algo não muito infantil, mas também não muito adulto, e optaram por ficar no meio termo o todo o tempo. Um dos produtores relatou que se fossem produzir o mesmo vídeo, só que desta vez endereçado à estudantes de graduação, assim como o grupo anterior relatou, este traria os assuntos de forma mais séria, com termos mais específicos, de forma mais complexa, e que talvez não fosse acessível para outros tipos de público. Este relato traz alguns indicativos de que o conceito de endereçamento tenha sido fator essencial para o desenvolvimento do vídeo pelo grupo.

Ainda de acordo com os produtores, a intenção foi utilizar o folclore brasileiro, por acreditarem que a criança poderia se interessar, para abordar o assunto científico visto em campo. Além da adição de narrativa, trabalharam com uma linguagem simples, acrescentaram legendas para os deficientes auditivos, trilha sonora, cortes e transições de filmagens dinâmicas.

Sendo assim, diante da análise dos elementos presentes nos vídeos, e das entrevistas com os produtores, é possível afirmar que houve apropriação do conceito de endereçamento em ambos os vídeos, pois foi possível perceber diversos elementos estéticos e técnicos destinados ao público infanto-juvenil. E, para atingirem tal público, utilizaram características que acreditavam fazer com que a relação dos espectadores com o vídeo fosse o de uma posição de aceitação, trabalhando forma e conteúdo concomitantemente. Os produtores apontaram que o conhecimento do conceito de endereçamento audiovisual trouxe um aporte teórico importante para se pensar no desenvolvimento de um vídeo para determinado tipo de público. Assim, relatam que o momento de formação vivenciado em sala de aula foi crucial para a elaboração das ideias presentes no produto final.

\subsection{O estudo de recepção audiovisual: as respostas dos estudantes do ensino básico}

Após e exibição dos vídeos, 60 alunos, participantes da feira de ciências, que assistiram a um dos dois vídeos exibidos, foram convidados a responder o questionário. Dentre o total, 19 alunos pertenciam ao nono ano, 25 do oitavo ano e 4 pertenciam ao sétimo ano. Apenas 12 alunos não informaram a série que cursavam. O objetivo foi identificar se o endereçamento, de fato, fez com que os espectadores se colocassem no lugar imaginado pelos produtores. Sabe-se que no processo comunicativo, proposto por Hall (2003), o público pode responder de forma diferente, mesmo quando todos pertencem a um mesmo grupo. Isso quer dizer que, mesmo os produtores tendo produzido um vídeo imaginado a um determinado público, este pode se mostrar sem o efeito previsto. Foram respondidos 26 questionários $\left(3\right.$ do $7^{\circ}$ ano, 7 do $8^{\circ}$ ano, 4 do $9^{\circ}$ ano e 12 de série não identificada) após a exibição do vídeo "Flora: a aventureira" e 34 questionários (1 do $7^{\circ}$ ano, 18 do $8^{\circ}$ ano e 15 do $9^{\circ}$ ano) do vídeo "Caexplora \& Curupira".

No caso do vídeo "Flora: a aventureira", a maioria das respostas apontaram que a produção permitia fácil compreensão do conteúdo, pois as explicações foram boas. Pontos positivos como a criatividade e a interação com o público 
também foram citados. O ponto negativo mais apontado foi a qualidade do som, e um fato interessante foi a de que 3 alunos responderam que a voz/jeito de falar dos personagens era muito infantilizada. Ou seja, mesmo os produtores imaginando o público do ensino fundamental um pouco mais infantil, ainda assim alguns alunos rejeitaram este tipo de representação.

Em relação ao que os espectadores mudariam na produção, apareceram respostas com a sugestão da adição de mais animais e plantas bem como seus nomes científicos, a presença de câmera escondida na mata, a presença de mais músicas, o aumento da duração do vídeo e da interação com o público, bem como melhoras na imagem, som e edição. Porém quatro respostas chamaram bastante atenção. Em duas delas, os estudantes responderam que acrescentariam ao vídeo a noção de como preservar o meio ambiente e outras duas apontaram que mudariam o jeito infantilizado que os personagens falam, ao alegarem ser muito forçado este jeito de falar. De fato, os produtores do vídeo imaginaram um público mais infantilizado, tanto que se tivessem produzido um vídeo para um público com idade maior, teriam utilizado uma personagem mais irônica, mais engraçada e com características voltadas mais para os adolescentes. Sendo assim, imaginaram um público formado por crianças menores, porém alguns integrantes desse mesmo público se afastaram da posição em que foram colocados. Além disso, na entrevista, os produtores justificaram que o objetivo do vídeo era o de apresentar os conteúdos científicos, sem entrar em questões maiores como a preservação, por exemplo.

Nas respostas sobre a identificação com algo presente no vídeo, 8 alunos disseram ter se identificado com a personagem Flora, pois lembrava o desenho "Dora: a aventureira", e, 9 alunos disseram ter se identificado com a música original retirada da trilha sonora da animação "O Rei Leão". Os produtores, na tentativa de aproximação com o público, escolheram um desenho muito comum entre as crianças e adolescentes e uma trilha sonora famosa entre eles. O que se pôde observar na hora da exibição foi uma vibração por parte dos alunos, em relação à trilha sonora, sendo que alguns até cantarolavam junto com o que estava sendo exibido na tela, podendo ser percebida uma certa aproximação e reconhecimento em relação ao que estavam assistindo.

Já no vídeo "Caexplora e Curupira", o destaque positivo que mais apareceu foi a abordagem sobre a preservação da natureza, ponto este enfatizado como sendo o objetivo principal do vídeo, segundo os próprios produtores. Este vídeo foi o mais bem aceito pelo público, nele, 22 alunos responderam que não mudariam nada em comparação com 11 do vídeo anterior. Em relação ao que mudariam no vídeo, citaram melhorias na imagem e som. Também escreveram que abordariam outros conteúdos como o ciclo da natureza, a poluição, que incluiriam a participação de mais pessoas na produção, cortariam algumas cenas repetitivas e melhorariam a atuação dos participantes. A presença de mais piadas também apareceu como açgo que acrescentariam ao vídeo, fato este, que segundo os produtores, seria um elemento de endereçamento para um público mais adolescente.

Em relação a pergunta sobre o que os alunos mais se identificaram no vídeo, o antagonista da história, interpretado pelo personagem do desmatador, foi o que mais apareceu. Cinco alunos disseram ter se identificado com este personagem pois ele demonstrava vontade de aprender algo novo. Já outros disseram que tinham presenciado pessoas cometendo os mesmos erros que o personagem. Três respostas apontaram uma identificação com a personagem da pesquisadora, devido ao seu interesse nos estudos, e três pelas personagens Caexplora e Curupira, por ter chamado atenção do desmatador.

Um fato a ser considerado em relação à importância de se conhecer o público-alvo, para a construção do endereçamento, se deu pelo relato de dois alunos. Eles escreveram que na própria escola onde os vídeos foram exibidos, também existia um projeto de preservação da natureza. E, mesmo os produtores do vídeo não tendo conhecimento do projeto, e por sorte terem abordado o tema, foi perceptível nas respostas dos alunos uma maior aceitação do vídeo. Assim, o ato de endereçar ganha importante destaque pois, quanto mais se conhece o público-alvo, como o contexto em que se encontram, seus gostos e preferências, por exemplo, a produção audiovisual pode ser desenvolvida com maiores chances de diálogo e aproximação com o público. Os produtores do vídeo não conheciam seu público real, apenas imaginaram uma turma de ensino 
fundamental, porém, se tivessem tido a chance de ter verificado a turma em questão, assim como a escola em que estavam alocados, entre outros aspectos, por exemplo, a construção do endereçamento poderia ter sido muito mais objetiva e assim, as chances de terem atingido os objetivos traçados se tornariam maiores.

Na questão que indaga os alunos em relação ao que tinham entendido após ver os vídeos, no questionário voltado para a produção "Flora: a aventureira", 18 das 26 respostas dos alunos apontaram o aprendizado sobre o conteúdo específico de ciências. Já no "Caexplora e Curupira", 20 das 33 respostas dos alunos indicaram que aprenderam mais sobre preservação da natureza. Apesar de a questão perguntar o que tinham entendido, não se pode ter certeza se, de fato, houve aprendizagem, pois não houve nenhum estudo posterior. Porém, o fato interessante fica por conta do número de alunos que responderam ter aprendido sobre o conteúdo específico de ciências (interações ecológicas), no primeiro vídeo, e sobre preservação, no segundo. Este, de fato, foi o objetivo almejado pelos produtores dos respectivos vídeos. Enquanto o objetivo do primeiro foi o de abordar um conteúdo escolar mais específico, mas, de forma mais leve e lúdica, o segundo aborda também os conteúdos, mas traz uma questão mais ampla, ao fazer relação com a preservação da natureza. Pode-se dizer, então, que o objetivo dos produtores foi atingido, em cada uma das produções. Assim, os alunos, em sua maioria, aceitaram o significado preferencial proposto pelos autores e expuseram isso em suas respostas, ao fazer uma leitura preferencial ou de dominância, como quando apontam o entendimento do conteúdo como o mais importante, no vídeo da "Flora" ou a questão da preservação no vídeo "Caexplora e Curupira".

As respostas dos questionários também expuseram vários pontos positivos nos vídeos e que estava dentro do planejamento pensado pelos produtores, como a adição de personagens e narrativas, na escolha de trilhas sonoras próximas à realidade dos estudantes, entre outros elementos que os alunos trouxeram ao terem sinalizado como sendo pontos que traziam identificação e/ou aproximação. Uma pequena parcela dos estudantes apontou um certo distanciamento em relação ao tom infantilizado dos personagens. A qualidade do som e imagem e outros elementos técnicos foram os que mais apareceram como principais pontos negativos. Este foi um ponto abordado por ambas as equipes como sendo uma das principais dificuldades ao se produzir um vídeo.

Desta maneira, no modelo proposto por Hall (2003), que aponta os processos de comunicação como um processo circular, a mensagem passa a ser um bem simbólico que circula como qualquer mercadoria, partindo do princípio de cinco etapas que podem ser codificadas e decodificadas: produção, circulação, distribuição/consumo e reprodução. É sob a forma discursiva que a circulação do produto se realiza, bem como sua distribuição para as diferentes audiências. Estas diferentes etapas possuem interdependência entre si, e se retroalimentam, ou seja, vários fatores atuam na hora da assimilação dos conteúdos midiáticos. É preciso, então, considerar o contexto sócio-histórico no qual os receptores estão inseridos. Assim, um vídeo utilizado em sala de aula pode não ser tão motivador quanto muitos estudos apontam (Moran, 1995; Gomes-Maluf \& Souza, 2008; Santos \& Gerbara, 2013), por exemplo, pois dependem de processos de codificação/decodificação dos significados, que por sua vez, precisam estar em sintonia com seus receptores para que possam fazer algum sentido. Todavia, mesmo apontando certo distanciamento, os espectadores indicaram terem gostado das produções que assistiram. Sendo assim, ao relembrar o processo de produção dos vídeos em campo, os produtores visaram um tipo de público e, após analisar as respostas dos questionários, pode-se dizer que atingiram seus objetivos, salvos alguns pontos de resistências dos alunos.

Sobre a importância do entendimento do conceito de endereçamento para a produção de vídeos para o ensino de ciências, um dos responsáveis pelo vídeo "Flora" relata que "pensar no endereçamento ajudou no sentido de se pensar em quão complexo deve ser aquilo que queremos transmitir (...) em vez de entupir de informação é interessante ouvir as pessoas também”. Assim como Hall (2003) e Ellsworth (2001) expõem em seus estudos, é importante conhecer seu público, e para isso, ouvi-los é um dos caminhos para que se possa estabelecer um diálogo. Outro integrante do mesmo grupo relatou que a partir do conhecimento do conceito de endereçamento conseguiu ter a "primeira percepção dentro do curso (de biologia) de 
que é possível fazer divulgação científica para um tipo de público específico. Algo diferente de avaliações voltadas apenas para a disciplina, por exemplo". No processo de produção que já traz um público específico desejado, se abre possibilidades de trabalhar o conteúdo científico, mas, dessa vez, abordado de outras formas e mais direcionado, e, foi esse o ponto positivo destacado pelos produtores. Isso não quer dizer que o sucesso do vídeo seja garantido, mas, a tentativa de aproximação e criação de diálogo com o público através de estudos, pesquisas, aprofundamento em relação ao universo em que estão inseridos, possa fazer com que a aceitação seja maior.

\section{Considerações Finais}

A importância da construção do endereçamento está justamente no fato de que se torna fundamental pensar na existência de um público a que se destina a produção e, a partir daí, tecer estratégias que tem como papel causar uma aproximação do público com a produção audiovisual. Em uma aula de ciências, ter noção deste conceito pode fazer com que o vídeo exibido possa atingir objetivos múltiplos no processo de ensino e aprendizagem, satisfazendo o objetivo do professor, que é o de ensinar ciência, e do aluno, possibilitando o entretenimento e aprendizado de forma mais abrangente. Dessa maneira, se abre a possibilidade de usufruir a obra audiovisual não apenas em busca do que o currículo pede, mas a partir das próprias experiências e interesses.

Esta pesquisa apontou que o estudo do endereçamento foi importante para adequar as escolhas estéticas e narrativas dos produtores ao público desejado, pois através do estudo de recepção, os alunos do ensino fundamental, em sua maioria, se colocaram no lugar pretendido pelos produtores, ou seja, na posição de alunos do ensino fundamental II. A ênfase para os conteúdos científicos no vídeo da "Flora" e a importância da preservação da natureza no vídeo da "Caexplora e Curupira" foi o objetivo traçado pelos produtores e a leitura preferencial feita pelos espectadores. A partir do momento que se tem entendimento da construção do endereçamento na produção de um vídeo, o professor pode se alertar para que tipo de público o vídeo será destinado, no sentido de prever (conhecendo seus alunos), e se os elementos que estão presentes na obra irão ou não entrar em um diálogo direto com o espectador. Quando este momento acontece, cria-se um ambiente de construção em conjunto, ou seja, há circularidade na mensagem, pois em ambos os lados (produção-recepção) há produção de sentidos. Já as resistências que apareceram, justificam a necessidade de se conhecer mais profundamente o público pretendido, visto que, mesmo sendo imaginado, é preciso pensar cada grupo com maiores detalhes as especificidades.

Para Hall (2003) a recepção das mensagens é entendida como um ato social onde convergem contextos e práticas culturais e comunicacionais, fazendo-se, através da negociação, a definição da realidade social. O estudo de recepção então parte da ideia da qual o espectador de uma obra audiovisual tem papel ativo no processo de construção de sentido. Por certo a mensagem carrega mecanismos de controle de sentidos, dependendo dos processos de codificação e dos contextos de exibição, mas, entender por que são aceitos, negociados ou sofrem oposição é dialogar com o receptor e assim, poder entender suas interpretações e necessidades.

Dessa maneira, tanto na produção da mensagem quanto em sua recepção, nada é transparente, ou seja, em cada pólo existem ideias pré-concebidas, contextos diferenciados, entre outros elementos que a tornam não transparente. Por consequência, os alunos, muitas vezes, podem fazer leituras de oposição, ao considerar os filmes chatos e entediantes. Nestes casos, o vídeo pode não despertar interessa no estudante justamente pela falta de elementos endereçados a ele, pois se preocupam apenas com as informações transmitidas, de forma neutra e linear, e não levam em consideração a realidade, contextos e experiências do espectador. Pensar nesses pontos em sala de aula é partir da ideia de que assim como os professores, os estudantes também são agentes ativos na produção de conhecimentos. 


\section{Referências}

Bardin, L. (2012). Análise de Conteúdo. Edições 70.

Bastos, W. G.; Rezende, L. A. C. \& Pastor, A. A. (2015). produção de vídeo educativo por licenciandos: um estudo sobre recepção fílmica e modos de leitura. Ensaio - Pesquisa em Educação em Ciências. 17(1), 39-58. doi.org/10.1590/1983-211720175170102

Bruzzo, Cristina. (1998). O documentário em sala de aula. Ciência \& Ensino, 3(1), 222-25.

Cabral, L. F. E. \& Pereira, M. V. (2019). Produção de vídeos em aulas de Biologia por alunos do Ensino Médio. Revista Educação Pública, 19(6). https://educacaopublica.cecierj.edu.br/artigos/19/16/producao-de-videos-em-aulas-de-biologia-por-alunos-do-ensino-medio

Duarte, R. (2005). Cinema \& Educação. (3a ed.) Autêntica Editora.

Ellsworth, E. (2001). Modo de endereçamento: uma coisa de cinema, uma coisa de educação também. In: Silva, T. (org.). Nunca fomos humanos: metamorfoses da subjetividade contemporânea. Autêntica.

Ferreira, M. S. \& Rezende Filho, L. A. C. (2021). Revisão de literatura: uso de obras audiovisuais no ensino de saúde mental na educação em Enfermagem. Research, Society and Development, 10(15). doi.org/10.33448/rsd-v10i15.22695

Freire, P. (1996). Pedagogia do Oprimido. Paz e Terra.

Fresquet, A. M. (2013). Cinema e educação: reflexões e experiências com professores e estudantes de educação básica, dentro e "fora da escola”. Autêntica.

Gancho, C. V. (2006). Como analisar narrativas. Ática.

Gomes-maluf, M. C. \& Souza, A. R. (2008). A ficção científica e o ensino de ciências: o imaginário como formador do real e do racional. Ciência \& Educação, 14(2), 271-282. doi.org/10.1590/S1516-73132008000200006

Hall, S. (2003). Codificação/Decodificação. In: Sovik, L. (Org.). Da diáspora: Identidades e mediações culturais (p. 387- 404). Editora UFMG.

Hegarty, M. (2004). Dynamic visualizations and learning: getting to the difficult questions. Learning and Instruction. 14, 343-351. doi:10.1016/j.learninstruc.2004.06.007

Lüdke, M. \& André, M. E. D. A. (2014). Pesquisa em Educação: abordagens qualitativas. (2a ed.).

Moran, J. M. (1995). O vídeo na sala de aula. Revista Comunicação e Educação, 2, 27-35. doi.org/10.11606/issn.2316-9125.v0i2p27-35

Pretto, N. L. (2013). Uma escola sem/com futuro. (8a ed.), EDUFBA.

Rezende Filho, L. A. C., Bastos, W. G., Junior, A. D. A. P., Pereira, M. V., \& de Sá, M. B. (2015). Contribuições dos estudos de recepção audiovisual para a educação em ciências e saúde. Alexandria: Revista de Educação em Ciência e Tecnologia, 8(2), 143-161. doi.org/10.5007/1982-5153.2015v8n2p143

Rezende, L. A. \& Struchiner, M. (2009). Uma proposta pedagógica para a produção e utilização de materiais audiovisuais no ensino de ciências: análise de um vídeo sobre entomologia. Alexandria: Revista de Educação em Ciência e Tecnologia, 2(1), 45-66. https://periodicos.ufsc.br/index.php/alexandria/article/view/37914/28951

Santos, P. C. \& Arroio, A. (2009). A utilização de recursos audiovisuais no ensino de ciências: tendências nos ENPECs entre 1997 e 2007. V Encontro Nacional de Pesquisa em Educação em Ciências - VII ENPEC - ATAS. Florianópolis, SC. https://www.researchgate.net/publication/290989975_A_utilizacao_de_recursos_audiovisuais_no_ensino_de_ciencias_Tendencias_nos_Enpecs_entre_1997_e 2007

Santos, J. N. \& Gerbara, M. J. F. (2013). Cinema como recurso didático: motivações nas aulas de ensino de ciências. IX Encontro Nacional de Pesquisa em Educação em Ciências - IX ENPEC - ATAS, http://abrapecnet.org.br/atas_enpec/ixenpec/atas/resumos/R1558-1.pdf

Vanoye, F. \& Goliot-lété, A. (2008). Ensaio sobre a análise fílmica. Papirus.

Vidal, F. L. K. \& Rezende Filho, L. A. C. (2010). Escolhendo Gêneros Audiovisuais para Exibições em Aulas de Ciências e Biologia: como os professores entendem a referencialidade da imagem. Alexandria: Revista de Educação em Ciência e Tecnologia, 3(3), 47-65. https://periodicos.ufsc.br/index.php/alexandria/article/view/38135/29084

Yin, R. K. (2001). Estudo de caso: planejamento e métodos. Bukman. 